\title{
Morphometry of blood monocytes in malignant lymphoma
}

\author{
RJ SOKOL, G HUDSON, J WALES, NT JAMES
}

From the Departments of Haematology, Anatomy, and Cell Biology, University of Sheffield, Sheffield

SUMMARY Morphometric methods were used to study the ultrastructure of blood monocytes in 23 patients with Hodgkin's disease, 12 patients with non-Hodgkin's lymphoma, and 20 normal subjects. The results were analysed using both univariate and multivariate methods. Both analyses supported the interpretation that the total mitochondrial contribution to the cellular ultrastructure was less in Hodgkin's disease than in the other two groups, with smaller mitochondrial volume fractions, volumes, and surface areas being found. In the patients with non-Hodgkin's lymphoma univariate analysis suggested that monocyte nuclei were larger, with more euchromatin and a relatively smaller heterochromatin-euchromatin interface; the cell profile area was larger and the surface to volume ratio was smaller compared with normal subjects. Morphological changes have not previously been described in blood monocytes in malignant lymphoma, but they may be the counterpart of the known mononuclear phagocyte dysfunction.

While there is ample evidence of dysfunction of mononuclear phagocytes in malignant disease, there are few reports of changes in their morphology ${ }^{1}$ and, hitherto, none has been described at the blood monocyte stage. The present investigation was undertaken to see whether any ultrastructural changes could be detected in blood monocytes in patients with malignant lymphoma. Morphometric techniques, similar to those used to quantify features of blood monocytes in normal subjects, ${ }^{2}$ were used with both univariate and multivariate methods of analysis.

\section{Material and methods}

Thirty five patients with malignant lymphoma and 20 normal subjects were studied. Twenty three patients had Hodgkin's disease, of whom 12 were men and 11 were women, with ages ranging from 18 to 70 years (mean $(\mathrm{SE})=39.0(3.9)$ years). Of these 23 patients, six had the lymphocyte predominant type of disease, six (all women) the nodular sclerosing type, and 11 the mixed cellularity type; all four disease stages were represented. Twelve patients had non-Hodgkin's lymphoma, of whom five were men and seven were women, with ages ranging from 34 to 75 years (mean $(\mathrm{SE})=54.3(2.9)$ ). In nine cases the disease was of the follicular centre cell type, and all four disease stages were represented.

Accepted for publication 18 April 1985
Among the normal subjects there were 10 men and 10 women, ages ranging from 17 to 52 years $(29 \cdot 3$ $(2 \cdot 2))$. All the patients with lymphoma were untreated except for one with Hodgkin's disease, who had been taking prednisolone for some weeks, and one with non-Hodgkin's lymphoma, who had been treated with allopurinol and brufen for four years. One of the patients with Hodgkin's disease had a concurrent carcinoma of the bronchus and one had had a papillary tumour removed from the bladder five days earlier. All the normal subjects were fit and were not taking any drugs.

About $10 \mathrm{ml}$ of venous blood was collected into 5 $\mathrm{ml}$ of $6 \%$ dextran 150 containing 500 units of pure heparin and gently mixed. Leucocytes were separated, fixed in $1.5 \%$ glutaraldehyde in $0.1 \mathrm{M}$ cacody-

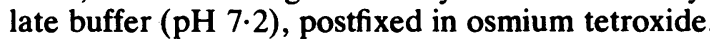
and processed by previously reported methods ${ }^{3}$ before embedding in Araldite and examination with a Philips 400T electron microscope. Monocytes were identified by their characteristic ultrastructural appearances. ${ }^{4}$ Surface pinocytic vesicles and the presence of typical monocyte granules were particularly useful features in identification: nuclear profile configuration and chromatin pattern contributed to a lesser extent. Micrographs were taken of nucleated cells in an independent, uniform random manner, about six being obtained from each of five different blocks from each subject.

Morphometric analysis of the monocytes was carried out as described elsewhere. ${ }^{2}$ The following vari- 
ables were studied: for the whole cell, profile area, volume, surface to volume ratio, and surface area; for the nucleus, volume fraction, profile area, volume, surface to volume ratio, and surface area; for the heterochromatin and euchromatin, volume fractions and volumes; and for the mitochondria, volume fractions of whole cell and cytoplasm, profile area, volume, surface to volume ratio, surface area and number of profiles per section, together with the profile area of individual mitochondria. In addition, random transect lengths of heterochromatin and euchromatin, together with the surface area of the theoretical heterochromatin-euchromatin interface per unit volume of nucleus, were studied as an indication of chromatin pattern.

Experimental means and their standard errors were calculated using standard statistical methods. ${ }^{5}$ Values expressed or measured as percentages were transformed using the arcsine function before statistical analysis. ${ }^{6}$

For univariate analysis, differences between means were tested at the 0.05 and 0.1 levels of probability using the two tailed Welch test. ${ }^{5}$ This test was selected on account of its robustness in dealing with non-normal distributions and its utility where variances of two populations may differ.

Statistical analysis on groups of mean values was also carried out using Hotelling's multivariate two sample $\mathrm{T}^{2}$ test, ${ }^{7}$ specific groupings of the variables being selected a priori on the basis of biologically meaningful "themes." The properties of the cell cytoplasm, nucleus, intranuclear chromatin, and mitochondria were analysed as independent groups with up to five variables being analysed simultaneously in each. Within these groups three data sets were available for analysis - namely, normal $v$ Hodgkin's disease; normal $v$ non-Hodgkin's lymphoma; and Hodgkin's $v$ non-Hodgkin's lymphoma.

$\mathrm{T}^{2}$ values for Hotelling's two sample test were calculated from the relation:

$$
\mathrm{T}^{2}=\frac{\mathrm{N}_{1} \mathrm{~N}_{2}}{\mathrm{~N}_{1}+\mathrm{N}_{2}}\left(\overline{\mathbf{X}}_{1}-\overline{\mathbf{X}}_{2}\right)^{\prime} \mathbf{S}^{-1}\left(\overline{\mathbf{X}}_{1}-\overline{\mathbf{X}}_{2}\right)
$$

where $N_{1}$ and $N_{2}$ were the numbers of subjects being compared, $\overline{\mathbf{X}}_{1}$ and $\overline{\mathbf{X}}_{2}$ the column vectors, and $S$ the common variance-covariance matrix for the combined samples. The null hypothesis $\mathrm{H}_{0}: \overline{\mathbf{X}}_{1}=\overline{\mathbf{X}}_{2}$ was accepted depending on the irregularity:

$$
\begin{aligned}
T^{2} \leqslant & \frac{\left(N_{1}+N_{2}-2\right) p}{N_{1}+N_{2}-p-1} F \\
& \left(\alpha ; p, N_{1}+N_{2}-p-1\right)
\end{aligned}
$$

or rejected otherwise, where $p$ was the number of sterological variables compared simultaneously and test function $F$ (for $\alpha$ level of significance with $p$ and $N_{1}+N_{2}-p-1$ degrees of freedom) was taken from appropriate tables. A significance level of $0 \cdot 1$ was adopted in view of the high discriminatory power of multivariate analysis.

\section{Results}

The Table shows the mean values and standard errors for the variables in the three groups. It also shows that several differences in individual variables at either 0.05 or 0.1 level of significance were found on univariate analysis. In patients with Hodgkin's disease mitochondrial volume fractions, volumes, and surface areas were significantly smaller than those of the other two groups and the number of mitochrondrial profiles was significantly less than in non-Hodgkin's lymphoma. In the patients with non-Hodgkin's lymphoma the profile area of the monocytes was larger than in the normal subjects with a smaller surface to volume ratio; their nuclei were larger than in the other groups (in terms of profile area, volume, and surface area) with a larger amount of euchromatin and a relatively smaller heterochromatin-euchromatin interface.

Multivariate analysis showed that for the group of mitochondrial variables (volume fraction of cytoplasm, profile area, volume, and surface area) the null hypothesis for the differences between normal and Hodgkin's disease and between Hodgkin's and non-Hodgkin's lymphoma could be rejected, again indicating that the mitochrondrial variables were significantly smaller in the patients with Hodgkin's disease. Differences between the other variable groups did not satisfy the criterion for statistical significance on multivariate analysis.

No conclusions could be drawn as to whether changes were more pronounced in particular histological subgroups or disease stages, the number of observations in individual categories being too small.

\section{Discussion}

In the present study the data were analysed by both univariate and multivariate methods, multivariate analysis being carried out on data for four biologically meaningful groups of variables (rather than on all possible combinations). Multivariate analysis has not been widely used in quantitative studies in clinical pathology, ${ }^{89}$ but it is a powerful statistical tool for dealing with a large group of variables of different type and may often have advantages over univariate analysis. Multivariate methods have a clearly identifiable level of significance in accepting or rejecting the null hypothesis, whereas in sequential testing of means by univariate analysis the chance of incorrectly rejecting a null hypothesis obviously increases with the number of comparisons made. 
Blood monocyte variables in patients with lymphoma and normal subjects

\begin{tabular}{|c|c|c|c|}
\hline \multirow[t]{2}{*}{ Variables } & \multirow{2}{*}{$\begin{array}{l}\text { Normal subjects } \\
(n=20)\end{array}$} & \multicolumn{2}{|l|}{ Patients with } \\
\hline & & $\begin{array}{l}\text { Hodgkin's disease } \\
(n=23)\end{array}$ & $\begin{array}{l}\text { Non-Hodgkin's lymphoma } \\
(n=12)\end{array}$ \\
\hline \multicolumn{4}{|l|}{ Cell } \\
\hline Profile area $\left(\mu \mathrm{m}^{2}\right)$ & $42 \cdot 8(0 \cdot 7)$ & $43 \cdot 2(0 \cdot 8)$ & $45 \cdot 7(1.3) \dagger$ \\
\hline Volume $(\mathrm{f})$ & $269.8(7 \cdot 1)$ & $273.0(7.7)$ & $293.6(13.1)$ \\
\hline Surface to volume ratio $\left(\mu \mathrm{m}^{2} / \mathrm{fl}\right)$ & $1.04(0.01)$ & $1.01(0.02)$ & $0.98(0.03) \dagger$ \\
\hline Surface area $\left(\mu \mathrm{m}^{2}\right)$ & $280 \cdot 8(5 \cdot 9)$ & $274 \cdot 8(7 \cdot 3)$ & $285.3(11.9)$ \\
\hline \multicolumn{4}{|l|}{ Nucleus } \\
\hline Volume fraction (\%) & $26 \cdot 2(0.01)$ & $25 \cdot 8(0 \cdot 01)$ & $26.7(0.02)$ \\
\hline Profile area $\left(\mu \mathrm{m}^{2}\right)$ & $13.8(0.2)$ & $13.7(0.3)$ & $14.9(0.5) \dagger \S$ \\
\hline Volume (f) & $70.6(2.0)$ & $70 \cdot 4(2 \cdot 3)$ & $79.6(4.0)^{*} \S$ \\
\hline Surface to volume ratio $\left(\mu \mathrm{m}^{2} / \mathrm{fl}\right)$ & $1.95(0.02)$ & $1.95(0.03)$ & $1.91(0.04)$ \\
\hline Surface area $\left(\mu \mathrm{m}^{2}\right)$ & $137.4(3 \cdot 5)$ & $135.6(2.9)$ & $150 \cdot 6(5 \cdot 2) \dagger \ddagger$ \\
\hline \multicolumn{4}{|l|}{ Heterochromatin (H) and euchromatin (E) } \\
\hline Volume fraction $(\mathrm{H})(\%)$ & $47 \cdot 1(0.02)$ & $46.9(0.05)$ & $45.7(0.06)$ \\
\hline Volume fraction (E) (\%) & $52.9(0.02)$ & $53.1(0.05)$ & $54.2(0.06)$ \\
\hline Volume $(\mathrm{H})(\mathrm{fl})$ & $33 \cdot 1(0.83)$ & $32.8(1.09)$ & $36 \cdot 2(1.65)$ \\
\hline Volume (E) (fi) & $37.5(1.36)$ & $37.6(1.66)$ & $43.4(2.90)+\S$ \\
\hline Transect length $(\mathrm{H})(\mu \mathrm{m})$ & $0.35(0.02)$ & $0.32(0.03)$ & $0.36(0.05)$ \\
\hline Transect length (E) $(\mu \mathrm{m})$ & $0.37(0.03)$ & $0.39(0.03)$ & $0.51(0.15)$ \\
\hline \multicolumn{4}{|l|}{$\begin{array}{l}\text { Surface area of heterochromatin- } \\
\text { euchromatin interface per unit volume of }\end{array}$} \\
\hline nucleus $\left(\mu \mathrm{m}^{2} / \mathrm{f}\right)$ & $3 \cdot 19(0 \cdot 09)$ & $3.20(0.07)$ & $2.93(0.11)+\S$ \\
\hline \multicolumn{4}{|l|}{ Mitochondria } \\
\hline Volume fraction of whole cell (\%) & $2.90(0.007)$ & $2.58(0.004)^{*}$ & $2.80(0.003)$ \\
\hline Volume fraction of cytoplasm (\%) & $4 \cdot 27(0 \cdot 010)$ & $3.78(0.006)^{*} \S$ & $4 \cdot 15(0.006)$ \\
\hline Profile area $\left(\mu \mathrm{m}^{2}\right)$ & $1.25(0.05)$ & $1.12(0.04) \uparrow \ddagger$ & $1.28(0.06)$ \\
\hline Volume (f) & $7.85(0.35)$ & $\pi<7.04(0.25) \dagger \ddagger$ & $8.25(0.48)$ \\
\hline Surface area $\left(\mu \mathbf{m}^{2}\right)$ & $115.6(4.4)$ & $\left(104 \cdot 4(3.0)^{*} \neq\right.$ & $119 \cdot 5(5 \cdot 5)$ \\
\hline Surface to volume ratio $\left(\mu \mathrm{m}^{2} / \mathrm{fl}\right)$ & $14.8(0.36)$ & $15.0(0.29)$ & $14.6(0.26)$ \\
\hline Profiles/section & $14.0(0.5)$ & $13.2(0.4) \neq$ & $14.6(0.3)$ \\
\hline Profile area of individual mitochondria $\left(\mu \mathrm{m}^{2}\right)$ & $0.09(0.004)$ & $0.09(0.002)$ & $0.09(0.003)$ \\
\hline
\end{tabular}

Values given as mean (SE).

Univariate analysis:

*significant difference from normal at the 0.05 level of probability

tsignificant difference from normal at the 0.1 level of probability

$\ddagger$ significant difference between Hodgkin's and non-Hodgkin's lymphoma at the 0.05 level of probability

$\S$ significant difference between Hodgkin's and non-Hodgkin's lymphoma at the 0.1 level of probability.

Multivariate analysis:

Isignificant differences from both other groups.

Both the univariate and multivariate analysis of the results (Table) support the interpretation that the total mitochondrial contribution to the cellular ultrastructure was significantly smaller in patients with Hodgkin's disease than in the other two groups, the reduction being of the order of $10 \%$. The values given in the Table provide no evidence that this was due to changes in size (profile area) or configuration (surface to volume ratio), and therefore suggest that it was more likely to be due to a reduction in the number of mitochondria. It may be relevant that previous studies have found some functional differences in the blood monocytes of patients with Hodgkin's disease $\mathrm{e}^{10-12}$ and it seems reasonable to suggest that the reduction in quantitative values for mitochondria noted here may be associated with a reduced energy potential in the monocyte with consequent effect on function. Further investigation of this point would appear important.

In the patients with non-Hodgkin's lymphoma univariate analysis of the results (Table) supports the interpretation that, compared with those of the other groups, the nuclei were increased in size, with more euchromatin and a smaller heterochromatineuchromatin interface per unit volume; the cell profile area was larger and the cell surface to volume ratio was smaller compared with normal subjects. By considering surface areas of spheres of equivalent volumes, we showed that the lower cell surface to volume ratio was not entirely due to the larger cell size, which implies that there was also a decrease in surface irregularity. All these changes would be consistent with enhanced monocyte activation. On multivariate analysis, however, the null hypothesis could not be rejected in relation to differences between the variable groups chosen. While caution must therefore be exercised in drawing inferences from the individual differences in the Table, it is pertinent to note that in skin window studies the macrophages of patients with lymphoma were bigger than normal, with larger and rounder nuclei, these features being particularly pronounced in patients with non-Hodgkin's lymphoma. ${ }^{13}$

Knowledge of the spatial organisation within cells 
is important in relation to understanding their function..$^{14}$ Although a diversity of functional changes in mononuclear phagocytes has been found in malignant disease, presumably reflecting an interaction of factors of host and tumour origin,' morphological changes in mononuclear phagocytes have not previously been reported at the blood monocyte stage and the present findings would seem of considerable importance in this respect. They also illustrate the potential of morphometric methods in clinical pathology.

We thank Miss Jane Stobbs and Miss Caroline Smith for secretarial assistance and the Trent Regional Health Authority for financial support.

\section{References}

' Sokol RJ, Hudson G. Disordered function of mononuclear phagocytes in malignant disease. J Clin Pathol 1983;36:31623.

${ }^{2}$ Sokol RJ, James NT, Wales J, Hudson G. Morphometry of human blood monocytes. Acta Anat (in press).

${ }^{3}$ James V. Stereological analyses of leukaemic cells. $\mathrm{Br} \mathrm{J}$ Haematol 1978;39:17-24.

4 Van der Rhee HJ. Blood monocytes and their differentiation into macrophages, epithelioid cells, and multinucleated giant cells. A morphological and cytochemical study. Heidelberg: Springer-Verlag, 1979: 1-16.
S Mack C. Essentials of statistics for scientists and technologists. New York: Plenum Press, 1967:3-51.

- Sokal RR, Rohlf FJ. Biometry: the principles and practice of statistics in biological research. 2nd ed. San Francisco: WH Freeman, 1981:427-8.

'Morrison DF. Multivariate statistical methods. 2nd ed. Kogakusha: McGraw Hill, 1976: 128-66.

' Baak JPA, Oort J. A manual of morphometry in diagnostic pathology. Berlin: Springer-Verlag, 1983:27-148.

' Baak JPA, Van der Ley G. Borderline or malignant ovarian tumour? A case report of decision making with morphometry. $J$ Clin Pathol 1984;37:1110-3.

${ }^{10}$ Leb L, Merritt JA. Decreased monocyte function in patients with Hodgkin's disease. Cancer 1978;41:1794-803.

" Estevez ME, Sen L, Bachmann AE, Pavlovsky A. Defective function of peripheral blood monocytes in patients with Hodgkin's and non-Hodgkin's lymphomas. Cancer 1980;46:299 302.

${ }^{12}$ Kohl S, Pickering LK, Sullivan MP, Walters DL. Impaired monocyte-macophage cytotoxicity in patients with Hodgkin's disease. Clin Immunol Immunopathol 1980; 15:577-85.

${ }^{13}$ Sokol RJ. Ultrastructure of mononuclear phagocytes in malignant lymphoma. Sheffield, England: University of Sheffield, 1985. Ph D Thesis: 238-41.

${ }^{14}$ Mclntosh JR. Modern cell biology: 2. Spatial organization of eukaryotic cells. New York: AR Liss Inc, 1983:15-558.

Requests for reprints to: Dr RJ Sokol, Regional Blood Transfusion Centre, Longley Lane, Sheffield S5 7JN, England. 